\title{
A Survey of Tobacco Smoking in University Students of Delhi / National Capital Region (NCR)
}

\author{
Anjana Goyal ${ }^{1}$, Anila Maria Varghese ${ }^{2}$, Zoha Siddiqui ${ }^{3}$, Ishika Chandra ${ }^{4}$, \\ Arjun Singh Verma ${ }^{5}$ M.D. Faizan ${ }^{6}$, Charchit Raj Singh ${ }^{7}$
}

\begin{abstract}
${ }^{1}$ Department of Biochemistry, Manav Rachna Dental College, Faridabad, Haryana, India. ${ }^{2}$ Department of Biochemistry, Manav Rachna Dental College, Faridabad, Haryana, India. ${ }^{3}$ Department of Biochemistry, Manav Rachna Dental College, Faridabad, Haryana, India. ${ }^{4}$ Department of Biochemistry, Manav Rachna Dental College, Faridabad, Haryana, India. ${ }^{5}$ Department of Biochemistry, Manav Rachna Dental College, Faridabad, Haryana, India. ${ }^{6}$ Department of Biochemistry, Manav Rachna Dental College, Faridabad, Haryana, India. ${ }^{7}$ Department of Biochemistry, Manav Rachna Dental College, Faridabad, Haryana, India.
\end{abstract}

\section{ABSTRACT}

\section{BACKGROUND}

The prevalence of smoking amongst university students is common and widespread. Generally, the period of smoking gets triggered with the onset of adolescence. This period is also called student period in which the most behavioural traits are created. Hukkah is also another popular product being used nowadays by students as it provides the extra feature of smoking flavoured tobacco. Hukkah is considered more risk prone than cigarettes due to more carbon monoxide poisoning, tarring heavy metals and carcinogens. A study conducted in Israel also showed that $41 \%$ of students were smoking tobacco through Hukkah and in yet another survey conducted among the students of America, it was found that $27 \%$ had smoked hukkah, which shows that the prevalence of smoking Hukkah has increased.

\section{METHODS}

The survey was conducted in one of the universities in Delhi/NCR during the academic year 2019 - 2020 by self-administering a questionnaire among the population of 200 students studying in various departments. The questionnaire included questions to analyse their knowledge, attitude and practice about smoking habits.

\section{RESULTS}

The analysis showed that there was no significant gender difference in smoking habits and was more or less same i.e. in the range of $80-82 \%$. The trend followed was also same in both the genders. Smoking period ranged from 18 years to 27 years. The reasons for smoking were different in older smokers then new smokers. Older ones used the habit for averting stress whereas new students adopted the habit out of pleasure and get trendy. Hukkah was also seen to be used mostly by new or younger groups during parties. Good part of the study was that a major part of students i.e. 59.5\% had intentions / desire to quit smoking due to its ill-effect on their health and remaining wanted to continue with smoking due to their own reasons.

\section{CONCLUSIONS}

University/college is a place where a student gets attracted to smoking habit due to reasons ranging from societal, physiological, psychological, mental pressures. In order to divert the attention of the students from adopting the habit of smoking, educational lectures among the college students should be organized on regular basis to raise awareness about the harmful effects of smoking on their health as well avoiding a wasteful expenditure of the hard-earned money, which can otherwise be used for maintaining a good health.

\section{KEY WORDS}

Smoking, Hukkah, Stress, Awareness, Boredom
Corresponding Author:

Dr. Anjana Goyal

H. No. 05, GF

Lilac-1, Sector-49,

Gurugram-122018,

Haryana, India.

E-mail: goyalanjana17@gmail.com

DOI: $10.14260 /$ jemds $/ 2020 / 613$

How to Cite This Article:

Goyal A, Varghese AM, Siddiqui Z, et al. A survey of tobacco smoking in university students of Delhi / national capital region (NCR). J Evolution Med Dent Sci 2020;9(38): 2815-2819, DOI: 10.14260/jemds/2020/613

Submission 30-05-2020, Peer Review 13-08-2020, Acceptance 19-08-2020, Published 21-09-2020.

Copyright (C) 2020 Anjana Goyal et al. This is an open access article distributed under Creative Commons Attribution License [Attribution 4.0 International (CC BY 4.0)] 


\section{BACKGROUND}

Tobacco is made by drying the leaves of tobacco plant. It contains nicotine which is an addictive drug. ${ }^{1}$ One of the major causes of preventable death among the developing countries is due to tobacco smoking/chewing. More than 6 million people die world over every year due to tobacco consumption, which causes major illness like cancer. India has almost $12 \%$ of world's smokers. ${ }^{2,3}$ The practice of tobacco smoking is high among the college/university students than those in general. The issue is further complicated by use of smokeless tobacco products in India. 4,5 The constituent of cigarette causes cardiovascular diseases (mainly coronary heart diseases) and many other health related risks like cancer (lung cancer) and respiratory diseases (mainly chronic obstructive pulmonary diseases). ${ }^{6}$ Smoking also causes osteoporosis, stroke, blindness, deafness and back pain. Tobacco smoking is also considered one of the factors for infertility in both men and women.7,8

In a pregnant lady, smoking can affect the baby's health before and after birth like- pre-term (early) delivery, still birth, low birth weight, sudden infant death syndrome. Effects of smoking are also seen as Ectopic pregnancy and orofacial clefts in infants. ${ }^{9}$ Despite people aware of all these impacts of tobacco smoking, they continue enjoying this habit. A study was conducted among the students of medical faculty of University of Prishtina in Kosova wherein they found that $53.2 \%$ of students were occasional smokers. This shows that number of occasional smokers was quite high in Kosova. ${ }^{10}$

A study was also conducted among the university students of Turkey wherein it was found that the mean smoking onset age of students was $16.34 \pm 2.72 \mathrm{yrs}$. In this age group, $27.9 \%$ had already adopted to smoking habit. This smokers' population constituted $46 \%$ men. It was further concluded that there was a higher rate of smoking among the males in the above population. ${ }^{1}$ Generally, the period of adolescence period becomes the onset period for smoking. ${ }^{12}$ This period is also called student period in which the most behavioural traits are transformed due to socio-cultural impacts like peer pressure ${ }^{13}$ etc. Some people start habit of smoking tobacco before the age of 18 years i.e. in much early age thereby it becomes difficult for them to quit this habit. Ultimately, this leads to their becoming a lifelong smoker. ${ }^{14}$ Not only above, they are certain other pressures created in mind through the advertisements, which act as a status symbol (youth becomes the main target of many tobacco companies). ${ }^{15,16,17}$ Many students do believe that tobacco smoking helps them relieving their boredom or helps in boosting/cheer up ${ }^{17}$ or in gaining self-confidence.18,19 The study has further revealed that some students smoke only in social gathering/parties or when they go out with friends. ${ }^{20}$ Among the smoker students, most of them had however stated that they were occasional smokers. ${ }^{21,22}$ In this way, all these students have had their own reasons or motivational stories for smoking.

Hukkah is another most popular tobacco product ${ }^{23}$ which is used to smoke flavoured tobacco. ${ }^{24}$ it was originated in India and $\operatorname{Iran}^{25}$ and is generally adopted by the youth population. ${ }^{26}$ Most people think that hukkah is not as harmful as that of cigarette and has less nicotine content than cigarette. It is less addictive which is a misconception ${ }^{27,28,29}$ In fact, hukkah is more risk prone than cigarette due to higher amount of carbon monoxide poisoning, tar of heavy metals and carcinogens. ${ }^{30}$ It causes lung cancer, cardiovascular disorders and low weight of new born ${ }^{31}$ The blood nicotine in hukkah smokers is equal to ten cigarettes smoked per day. ${ }^{32}$

A study was conducted among the student population of Israel wherein it was found that $41 \%$ of students smoked tobacco through hukkah ${ }^{33}$. In another study conducted among the student population of America, it was found that $27 \%$ of students' population were using hukkah. ${ }^{34}$ The reason of increased usage of hukkah among present day students is due to socio-cultural reasons mainly peer pressure in pubs and clubs $^{35}$ for show-casing fashion and reflect a superlative socioeconomic status ${ }^{36}$. The youngsters are fascinated to hukkah the most for the reasons that it gives different flavors. ${ }^{37,38} \mathrm{~A}$ study was conducted in two U.S. cities, Richmond, Virginia, and Memphis, Tennessee, the respondents were majority Men and college students and they found that $67 \%$ currently smoked. ${ }^{39}$

\section{METHODS}

The survey was conducted in 'Manav Rachna University, Faridabad' of Delhi/NCR during the lock down period of Covid19 pandemic for year 2019-2020 after taking clearance from Head of the Institute. This study was made by selfadministering a set of questionnaires in the form of Google Forms after seeking the consent of students on social medium platform among randomly selected 200 students studying in various faculties like Dental (70 students), Engineering (66 students) and Management (64 students) They included 128 males and 72 females. The average age of the sample was 22.5 \pm 4.5 years. The questionnaire included 15 questions on knowledge, attitude and practice related to smoking habits, current status, the onset age of adopting smoking habits, the compulsions/reasons of smoking, hukkah usage, electronic cigarettes and/or any other kind of tobacco smoking, number of cigarettes smoked per day, former smokers, attempt and intentions of quitting smoking, knowledge and attitude about smoking, indulgence of tobacco companies to attract young university students through their advertisements.

\section{Statistical Analysis}

To determine the various proportions in the sample size during the survey, a simple technique of calculating the percentages of various attributes such as practices, attitudes and knowledge were used with respect to smokers' males and females. This helped us to analyze and compare the proportion of males and female students among themselves and also within by way of habit and all other attributes.

\section{RESULTS}

Of the total of 200 surveyed students (128 males and 72 females), the total number of smokers were 163 (106 males and 57 females). 


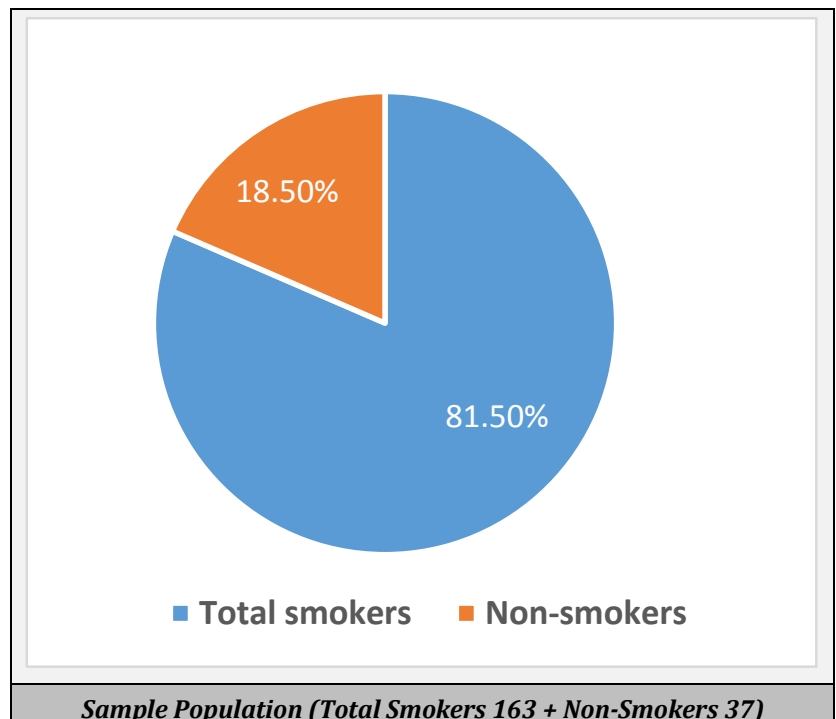

Sample Population (Total Smokers 163 + Non-Smokers 37)

It was found that out of total males, $82.81 \%$ males and out of total females, $79.16 \%$ females were using one or the other type of tobacco product.

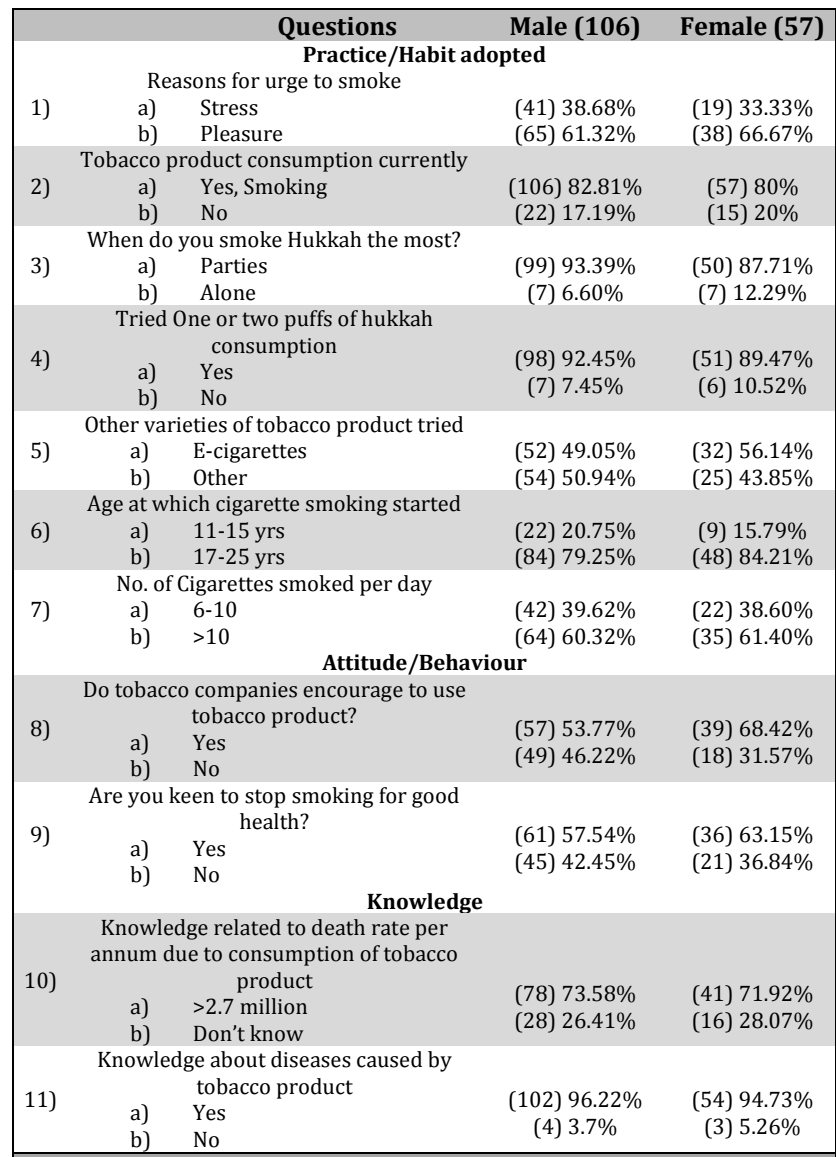

Table I. Students' Knowledge, Attitude and Practice towards Smoking

Further, it was noticed that in the sample size, a very small percentage of people were old/former smokers and most of these were the ones who had adopted the habit in recent time means were new/current smokers. Thus, from the data, it was found that males constituted $7.55 \%$ old/former smokers and $92.45 \%$ new/current smokers, whereas in females, $5.26 \%$ were old/former smokers and $94.74 \%$ were new/current smokers.

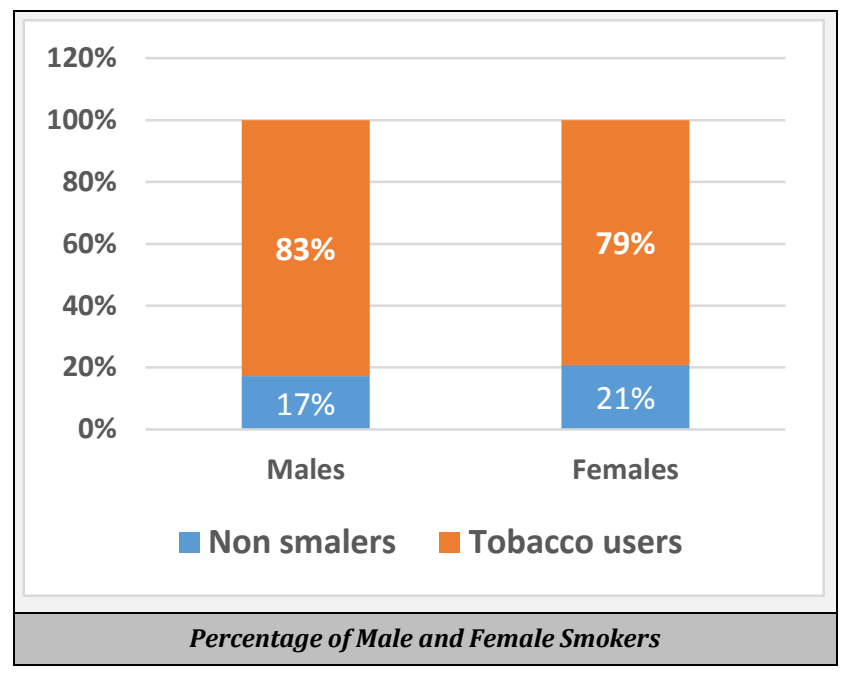

DISCUSSION

This study was conducted to establish the reasons prevailing for smoking among the students studying in a university of Delhi/NCR and the latest outlook of tobacco products adopted by them. Study done among Somalis in Minnesota showed that the prevalence of tobacco use among Somalis is high i.e, 50\%. A similar study was done among young adults in Palestine, they found that male smokers were more than female smokers, they also found that $70 \%$ males started smoking at an earlier age i.e. before the age of 19 years. ${ }^{40}$ The analysis showed that there was no significant gender difference in the smoking habits as the percentage of male and female students involved in smoking was found almost same i.e., in the range of $80-82 \%$. It revealed that the trend followed in both the genders was same. Among the students involved in smoking, smoking period ranged from 18 years to 27 years. The reason for smoking in older students i.e., between $22-27$ years was mainly the stress and some of them smoked due to passion/in parties only. However, in younger students' i.e. between 18-22 years, smoking was adopted during various parties, for pleasure with friends as it was fashionable and trendy. In general, analysis showed that most of the students began smoking habit as a trend in students' community for pleasure, social status and to overcome stressful situations. Hukkah was mostly used among the university students during parties.

Average period of starting smoking in students ranged from 14 to 20 years, however a very few students started smoking at a very early age before 13 years mostly to have an experience of smoking. The number of cigarettes smoked per day by any student in the given sample size was on an average $10.5 \pm 4.5$. Desire to quit smoking was also found quite remarkable as the study showed that $59.5 \%$ of the total students expressed their willingness due to its adverse effects on health and falling prey to addiction. $40.5 \%$ did not show any inclination to leave this habit as they had enjoyed this habit and some continued to relax.

It is therefore seen that justification given for adopting smoking habits included boredom and pleasure among the younger university students, while persistence of smoking in slightly older generation of university students was their stress. The trend of smoking among male and female 
population was same and there was no major statistical difference found in male and female students.

In view of all the factors discussed herein above, points that emerge for future discussion are as under

1. Are there methods to alienate new young university students from societal, physiological, psychological, mental factors?

2. Shall new educational tips be helpful in changing the minds of young university students to understand the irreversible impact of illness leading sometimes to death?

3. Can the money spent on tobacco smoking be used for other healthy purposes?

4. Should the government itself not take an initiate to nip the bud by stopping the production of tobacco products so as to save the youngsters from falling into trap?

\section{CONCLUSIONS}

Smoking is a common phenomenon which gets triggered during student life, and universities/colleges are the potential areas for inculcating smoking habits. There is statistically no significant gender difference in smoking habit during this period. Reasons for adopting smoking by students can be attributed to societal, physiological, psychological, mental pressures, to overcome stress etc. During this period, educational lectures in student community should necessarily be organized to raise awareness about the harmful effects of smoking which will reduce the prevalence of smoking and avoid addiction to it. This will also help to avoid wasteful expenditure by the young in name of fashion / trend and will help in motivating them to lead a healthy lifestyle.

Financial or Other Competing Interests: None.

\section{REFERENCES}

[1] Guidelines from Australian Government https://www.health.gov.au/health-topics/smoking-andtobacco/about-smoking-and-tobacco/what-is-smokingand-tobacco

[2] World Health Organization. The MPOWER: a policy package to reverse the tobacco epidemic. Geneva, Switzerland: Tech Rep Health Organization 2008. https://www.who.int/tobacco/mpower/mpower_englis h.pdf

[3] Chandrupatla SG, Tavares M, Natto ZS. tobacco use and effects of professional advice on smoking cessation among youth in India. Asian Pac J Cancer Prev 2017;18(7):1861-7.

[4] Fotouhi A, Khabazkhoob M, Hashemi $\mathrm{H}$, et al. The prevalence of cigarette smoking in residents of Tehran. Arch Iran Med 2009;12(4):358-64.

[5] Reddy KS, Gupta PC. Report on tobacco control in India. New Delhi, India: Ministry of Health and Family Welfare 2004.

[6] Leone A, Landini L, Leone A. What is tobacco smoke? Sociocultural dimensions of the association with cardiovascular risk. Curr Pharm Des 2010;16(23):25107.

[7] Action on Smoking and Health. Smoking statistics: who smokes and how much? London: ASH 2016. http://www.ash.org.uk/files/documents/ASH_106.pdf

[8] US Department of Health and Human Services. The health consequences of smoking: a report of the surgeon general. Atlanta, GA: US Department of Health and Human Services, Centers for Disease Control and Prevention, National Center for Chronic Disease Prevention and Health Promotion, Office on Smoking and Health 2004: p. 62.

[9] Action on Smoking and Health. Smoking and reproduction. London: ASH 2013. http://www.ash.org.uk/files/documents/ASH_112.pdf

[10] CDC guidelines https://www.cdc.gov/tobacco/data_statistics/sgr/50thanniversary/pdfs/fs_smoking_reproduction_508.pdf

[11] Griesbach D, Amos A, Currie C. Adolescent smoking and family structure in Europe. Soc Sci Med 2003;56(1):4152.

[12] Karadoğan D, Önal Ö, Kanbay Y. Prevalence and determinants of smoking status among university students: Artvin Çoruh University sample. PLoS ONE 2018;13(12):e0200671.

[13] Heydari G, Ramezankhani A, Masjedi M. Evaluation of the smoking habit among male students of all faculties of the Shahid Beheshti University and Shahid Beheshti Medical Science University during 2008. J Res Med Sci 2010;34:132-6.

[14] Majidpour A, Hamidzadeh Y, Abbasgholizadeh N, et al. Prevalence and causes of tendency to cigarette smoking among students in Ardabil University of Medical Sciences. J Ardabil Univ Med Sci 2006;5:266-70.

[15] Centers for Disease Control and Prevention (CDC). Use of cigarettes and other tobacco products among students aged 13-15 years--worldwide, 1999-2005. MMWR Morb Mortal Wkly Rep 2006;55(20):553-6.

[16] Written and reviewed by the MediResource Clinical Team. https://www.medbroadcast.com/channel/smoking/you th-and-smoking/why-teens-and-kids-start-smoking

[17] Piko BF, Wills TA, Walker C. Motives for smoking and drinking: country and gender differences in samples of Hungarian and US high school students. Addict Behav 2007;32(10):2087-98.

[18] Wills TA, Sandy JM, Shinar O. Cloninger's constructs related to substance use level and problems in late adolescence: a mediational model based on self-control and coping motives. Exp Clin Psychopharmacol 1999;7(2):122-34.

[19] Moran S, Wechsler H, Rigotti NA. Social smoking among US college students. Pediatrics 2004;114(4):1028-34.

[20] Schane RE, Glantz SA, Ling PM. Nondaily and social smoking: an increasingly prevalent pattern. Arch Intern Med 2009;169(19):1742-4.

[21] Harris KJ, Wilson T, Ahluwalia JS. A qualitative analysis of college students' smoking: perceptions and interest in change. Poster presented at: Annual Meeting of the Society for Research on Nicotine and Tobacco February $23,2002$. 
[22] Wetter DW, Kenford SL, Welsch SK, et al. Prevalence and predictors of transitions in smoking behavior among college students. Health Psychol 2004;23(2):168-77.

[23] Hines D, Fretz AC, Nollen NL. Regular and occasional smoking by college students: personality attributions of smokers and nonsmokers. Psychol Rep 1998;83(3 Pt 2):1299-306.

[24] Creamer MR, Loukas A, Li X, et al. College students's perceptions and knowledge of hookah use. Drug Alcohol Depend 2016;168:191-5.

[25] Al Rashidi M, Shihadeh A, Saliba N. Volatile aldehydes in the mainstream smoke of the narghile waterpipe. Food Chem Toxicol 2008;46(11):3546-9.

[26] Chaaya M, El-Roueiheb Z, Chemaitelly H, et al. Argileh smoking among university students: a new tobacco epidemic. Nicotine Tob Res 2004;6(3):457-63.

[27] Ward KD, Eissenberg T, Gray JN, et al. Characteristics of US waterpipe users: a preliminary report. Nicotine Tob Res 2007;9(12):1339-46.

[28] Chan A, Murin S. Up in smoke: the fallacy of the harmless Hookah. Chest 2011;139(4):737-8.

[29] Primack BA, Sidani J, Agarwal AA, et al. Prevalence of and associations with waterpipe tobacco smoking among U.S. university students. Ann Behav Med 2008;36(1):81-6.

[30] Prevention CfDCa. Fact sheet on hookah smoking. 2011.

[31] Ray CS. The hookah - the Indian waterpipe. Current Science 2009;96(10):1319-23.
[32] https://www.mayoclinic.org/healthy-lifestyle/quitsmoking/expert-answers/hookah/faq-20057920

[33] Knishkowy B, Amitai Y. Water-pipe (narghile) smoking: an emerging health risk behavior. Pediatrics 2005;116(1):e113-9.

[34] Neergaard J, Singh P, Job J, et al. Waterpipe smoking and nicotine exposure: a review of the current evidence. Nicotine Tob Res 2007;9(10):987-94.

[35] Vorsano S, Ganz I, Eldor N, et al. Waterpipe tobacco smoking among school children in Israel: frequency, habits and attitudes. Harefuah 2003;142(11):736-41.

[36] Rice VH, Weglicki LS, Templin T, et al. Predictors of Arab American adolescent tobacco use. Merrill Palmer $Q$ 2006;52(2):327-42.

[37] Palamar JJ, Zhou S, Sherman S, et al. Hookah use among U.S. high school seniors. Pediatrics 2014;134(2):227-34.

[38] Amin TT, Amr MAM, Zaza BO, et al. Predictors of waterpipe smoking among secondary school adolescents in Al Hassa, Saudi Arabia. Int J Behav Med 2012;19(3):324-35.

[39] Giuliani KKW, Mire OA, Jama S, et al. Tobacco use and cessation among Somalis in Minnesota. Am J Prev Med 2008;35(6 Suppl):S457-62.

[40] Seir RA, Kharroubi A, Ghannam I. Prevalence of tobacco use among young adults in Palestine. Eastern Mediterranean Health Journal 2020;26(1):75-84. 